\title{
Do Investors Put Their Money Where Their Mouth Is? Stock Market Expectations and Investing Behavior*
}

\author{
Christoph Merkle $\rfloor^{\dagger}$ Martin Weber ${ }^{\ddagger}$
}

First version: February 2011 — This version: August 2012

\begin{abstract}
There is a large gap between what finance models predict for individual investor behavior and what can be observed in their actual behavior. Portfolio theory assumes that investors form expectations about return and risk of securities and select portfolios according to their expectations and risk preferences. As a consequence they should hold broadly diversified portfolios and trade very little. But instead, private investors have been shown to hold underdiversified portfolios, to trade frequently, to take high idiosyncratic risk, and to gamble in the stock market. To understand this striking differences the investment process itself needs greater scrutiny. How do real investors use their beliefs and preferences in investing decisions? We examine this question using a panel survey of self-directed online investors at a UK bank. The survey asks for return expectations, risk expectations, and risk tolerance of these investors in three-month intervals between 2008 and 2010. We combine the survey data with investors' actual trading data and portfolio holdings. We find that investor beliefs have little predictive power for immediate trading behavior. However, portfolio risk levels and changes are systematically related to return and risk expectations. In line with financial theory, risk taking increases with return expectations and decreases with risk expectations.
\end{abstract}

JEL-Classification Codes: D81, G02, G11

Keywords: Expectations, Beliefs, Risk, Return, Trading Behavior, Portfolio Choice

${ }^{*}$ We are grateful to Barclays Stockbrokers for providing access to their online investor client base, and to Barclays Wealth Behavioural Finance team for joint design and execution of the survey. We thank Daniel Egan, Christian Ehm, Greg Davies, Victor Fleisher, participants of the 2011 Boulder Summer Conference on Consumer Financial Decision Making and the 2011 SPUDM Conference, and seminar participants in Mannheim and Luxemburg. For research assistance we thank Robin Cindori. Research reported in this article was supported by the European Institute of Savings (OEE) and Deutsche Forschungsgemeinschaft (DFG, grant We993).

${ }^{\dagger}$ Department of Banking and Finance, University of Mannheim (corresponding author: chmerkle@mail.uni-mannheim.de).

${ }^{\ddagger}$ Department of Banking and Finance, University of Mannheim, and CEPR, London (weber@bank.bwl.uni-mannheim.de). 


\section{Introduction}

There is a large gap between what finance models predict for individual investor behavior and what can be observed in their actual behavior. Portfolio theory assumes that investors form expectations about return and risk of securities and select portfolios according to their expectations and risk preferences (Markowitz, 1952). As a consequence they should hold broadly diversified portfolios and trade very little. But instead, private investors have been shown to hold underdiversified portfolios (Goetzmann and Kumar, 2008), to trade frequently (Odean, 1999; Barber and Odean, 2000), to take high idiosyncratic risk (Calvet, Campbell, and Sodini, 2007), and to gamble in the stock market (Kumar, 2009). There is also evidence, that they use investment strategies different from pure mean-variance optimization (Lewellen, Lease, and Schlarbaum, 1977; Grinblatt and Keloharju, 2000). Often these deviations have been explained by specific psychological biases, e.g. excessive trading by overconfidence (Odean, 1998; Glaser and Weber, 2007).

However, this way one learns very little about the actual decision making process people go through when they invest. How do investors use their beliefs and preferences in this process? Empirically, there is only scarce evidence on this question as the input parameters are hard to obtain. The economic paradigm of revealed preferences states that beliefs and preferences can be inferred from observed actions (Samuelson, 1938). But this already implies that they are perfectly converted into actions. In order to reveal whether and where this transfer fails, direct information on beliefs and preferences are needed. To this end we collect return and risk expectations in a repeated panel survey of self-directed private investors at a large UK online brokerage provider. In three-month intervals these investors are queried for numerical and qualitative expectations and their risk tolerance. We then match expectations of investors to their actual transactions in their online brokerage accounts. We observe volume, timing, and direction of all trades within the survey period, and are able to calculate portfolio holdings of participants. 
We develop different measures of financial risk taking based on trading behavior and portfolio holdings of investors. In a first step, we consider the direction of stock trading and calculate the ratio of buys versus sells. This corresponds to an increase or decrease of investors' total equity position. We find that the absolute levels of expectations for market return and risk do not predict buying and selling behavior. An explanation could be that previous expectations are already reflected in investors' portfolios and there is no need for investors to engage in further transactions. We therefore also test whether changes in expectations explain buying and selling behavior corresponding to trades reflecting changes in portfolios. Indeed, improving return expectations have a positive impact on buy-sell ratios. Thus, quite intuitively, positive return expectations foster buying activity, but there is no effect of changes in risk expectations or risk attitude on buy-sell ratios.

While immediate trading behavior and direction of trade is a means to alter one's risky position, we also directly investigate portfolio risk. We calculate portfolio volatility and beta for investors in our panel as standard risk measures. This is complemented by additional measures such as relative volatility and average component volatility (Dorn and Huberman, 2005). We consider both, levels of portfolio risk at the point in time of survey rounds and changes in portfolio risk between survey rounds. Levels of risk taking of investors can be well explained by their beliefs, preferences and demographics. All portfolio risk measures are positively related to return expectations and risk tolerance, and negatively related to risk expectations, age, and wealth of investors. These results are consistent with financial theory and previous literature.

An advantage of our dataset is that it allows studying the dynamics of this relationship between expectations and risk taking, i.e. whether investors react to changes in expectations by changing their portfolio composition and thus alter risk exposure. For the volatility measures this is the case, as we find a positive change in volatility when return expectations improve and a negative change if investors expect increasing stock market risk. The relationship is weakest for short-term volatility and portfolio beta, indicating that investors 
manage their portfolios rather based on long-term volatility as a proxy for risk taking. Our results are robust to several alternative specifications including the use of lagged values to address endogeneity concerns. Risk tolerance remains insignificant in most of our regressions (both levels and changes), which sheds some light on the debate, whether investors can translate their level of risk aversion into an adequate portfolio choice (Ehm, Kaufmann, and Weber, 2012).

Finally we combine the perspectives of trades and portfolio risk and analyze the volatility of transactions by investors. This allows us to gain a deeper understanding of how investors regulate their portfolio risk. The analysis reveals that more optimistic investors shift part of their investments to more volatile securities. In addition to expanding their total equity position by purchases in excess of sales, they also buy riskier assets. This is consistent with the finding that portfolio volatility not just passively moves with market volatility, but also relative portfolio volatility increases for optimistic investors.

We continue with a theoretical motivation and an overview of related literature in section 2 , followed by a description of the data sets, which contains two main sources, the survey and the trading data. In section 4 we present results about the relationship between investor expectations and trading behavior, which we then discuss in section 5. A final section concludes.

\section{Theory and literature}

People acting on their beliefs and preferences are such a basic assumption in economic theory that it has seldom been contested. Exemplarily, portfolio theory as the canonical finance model posits that investors form expectations about return and risk of securities and then choose an optimal portfolio according to their risk preferences (Markowitz, 1952). We will now in a more formal but simple way derive directional predictions for the influence of return expectations, risk expectations, and risk tolerance on financial risk taking behavior. 
We assume an investor to have power utility defined over wealth $W$ of the form $U(W)=$ $W^{1-\theta}-1 /(1-\theta)$. Power utility has the desirable property of declining absolute risk aversion and constant relative risk aversion, which is most consistent with real world observations. The investor in a simple two-period economy faces the budget constraint $W_{1}=W_{0}\left(1+r_{0,1}\right)$, implying that the only source of wealth at time $t=1$ is wealth in $t=0$ plus the return earned on wealth. The corresponding maximization problem thus is:

$$
\max E_{0}\left[\left(W_{0}\left(1+r_{0,1}\right)\right)^{1-\theta} /(1-\theta)\right] .
$$

When instead of expression 1 the logarithm of this expectation is maximized, the problem simplifies to (for a detailed derivation cp. Campbell and Viceira, 2002):

$$
\max \ln E_{0}\left(1+r_{0,1}\right)-\frac{1}{2} \theta \sigma_{0}^{2}
$$

where $\sigma_{0}^{2}$ is the conditional variance of the log return. In expression 2 the ingredients of the maximization problem are visible; the investor trades off expected return against expected risk (variance of returns). The parameter $\theta$ of the utility function describes the investor's relative risk aversion.

With only two assets, a risky asset $\mathrm{s}$ and a riskless asset $\mathrm{f}$, return on wealth is $r_{0,1}=$ $r_{f, 0,1}+w_{s, 0}\left(r_{s, 0,1}-r_{f, 0,1}\right)$, where $w_{s, 0}$ represents the weight an investor puts on the risky asset. A little complication arises from the fact that power utility operates under the assumption of lognormally distributed returns, but log return on wealth cannot be expressed as a linear combination of the log return of the two assets. Instead, Campbell and Viceira (2002) suggest a Taylor approximation to rewrite (2) in the form

$$
\max w_{s, 0}\left(E_{0} r_{s, 0,1}-r_{f, 0,1}\right)+\frac{1}{2} w_{s, 0}\left(1-w_{s, 0}\right) \sigma_{0}^{2}+\frac{1}{2}(1-\theta) w_{s, 0}^{2} \sigma_{0}^{2},
$$


which can be solved by

$$
w_{s, 0}=\frac{E_{0} r_{s, 0,1}-r_{f, 0,1}+\sigma_{0}^{2} / 2}{\theta \sigma_{0}^{2}}
$$

The equation implies that the share of risky investment should increase with expected returns for the risky asset, and decrease with risk expectations and risk aversion. This result can be generalized to a multi-asset or multi-period framework and is fairly robust to the relexation of several of the chosen assumptions. A simple mean-variance optimization comes to the same conclusions, as does - from a slightly different angle - risk-value theory (Sarin and Weber, 1993). We take the results of this model as a prediction for the role of expectations and risk preferences in investing behavior.

Empirically, risk taking behavior of individual investors has been studied using different approaches and datasets. Vissing-Jorgensen (2003) analyzes a US individual investor survey by UBS/Gallup and finds a strong positive effect of expected return on equity share in selfreported investor portfolios. Dorn and Huberman (2005) report portfolio volatilities for a sample of German brokerage clients and identify risk aversion as most predictive for portfolio volatility. Moreover, younger, self-employed, less sophisticated, and poorer investors tend to hold more risky portfolios. Calvet, Campbell, and Sodini (2007) examine disaggregated wealth data covering the entire Swedish population and show a positive impact of wealth, income, and education on risk taking measured by portfolio volatility 1 They also break down portfolio risk in its various components and reveal interesting patterns of risk taking. In a follow-up study, Calvet, Campbell, and Sodini (2009) present evidence on rebalancing suggesting that investors actively control their share of risky investments and offset changes brought about by passive market variations.

\footnotetext{
${ }^{1}$ The seemingly contradictory results might be explained by the different composition of the datasets. While Dorn and Huberman (2005) analyze stock portfolios, where wealth and financial sophistication usually lead to a better diversification (and thus less risk), Calvet, Campbell, and Sodini (2007) use total wealth portfolios for which wealth and sophistication typically lead to a greater equity share (and thus more risk).
} 
While this literature addresses risk taking behavior of private investor, it lacks a systematic study of the input variables we are interested in: individual investor beliefs in form of return and risk expectations, and investor risk preferences. Closest related to our study is the work by Amromin and Sharpe (2009), Weber, Weber, and Nosić (2012), Hoffmann, Post, and Pennings (2010), and Guiso, Sapienza, and Zingales (2011). Similar to us Amromin and Sharpe (2009) use panel data, in their case coming from the Michigan Survey of Consumer Attitudes. However, they analyze self-reported portfolio shares of survey participants and do not have access to their transactions or actual portfolios. They concentrate on the interrelation of return expectations and risk expectations, but also provide some evidence of the influence of these variables on portfolio composition. Consistent with financial theory higher return expectations and lower risk expectations increase the share of equity in portfolios of investors. Hoffmann, Post, and Pennings (2010) study an investor survey in the Netherlands which is matched to brokerage account data. Their data spans a time period from April 2008 to March 2009 and survey rounds are administered monthly. By eliciting expectations and portfolio characteristics, Hoffmann, Post, and Pennings (2010) establish a link between the beliefs of investors and their trading behavior concentrating on investor performance. They find that high return expectations, low risk expectations, and low risk tolerance contribute to high returns and Sharpe ratios.

Guiso, Sapienza, and Zingales (2011) in their analysis concentrate on risk aversion measured by a qualitative and a quantitative approach. They report a substantial increase of risk aversion in the financial crisis compared to pre-crisis levels. Ownership of risky assets is negatively related to risk aversion. Guiso, Sapienza, and Zingales (2011) suggest psychological factors as drivers of risk aversion, as they are able to rule out alternative explanations such as wealth or background risk.

In a previous analysis of our dataset, Weber, Weber, and Nosić (2012) report a relationship between expectations and investing decisions. They analyze a survey question which asks participants to split a hypothetical amount of $£ 100,000$ between an investment in the 
UK stock market and a riskless asset. With this investment task they are able to show a strong influence of changes in expectations and risk attitude on changes in the proportion of risky investment; this influence is in the expected direction, increases in expected returns or risk tolerance lead to an increase in risky investment, while higher risk expectations render investors more cautious. We extend this research by relating return and risk expectations to the actual trades and portfolios of investors. By analyzing various aspects of investing behavior, we present a more complete portrayal of the underlying relationships. We also exploit the full time series of the survey which was not available to the earlier study by Weber, Weber, and Nosić (2012).

\section{Data}

We obtain survey responses and transaction data for a sample of clients at Barclays Stockbrokers, a UK direct brokerage provider. Barclays is one of the largest brokers in the UK and attracts a wide variety of customers (for demographic characteristics of its clients see Egan, Merkle, and Weber, 2010). The accounts are self-directed in the sense that customers can inform themselves on special webpages provided by the bank, but receive no direct investment advice. Most transactions are processed online.

\subsection{Survey data}

In collaboration with Barclays Wealth, we conduct a repeated survey taking place every three months, beginning in September 2008 and ending in September 2010. Figure 1 shows the development of the UK stock market represented by the FTSE all share index and the timing of survey rounds. Our panel consists of nine rounds covering a time period of highly volatile market environment. We thus expect participants to express changing beliefs about market prospects; in the standard model this would in turn lead to changes in their portfolios. 
In the initial survey a stratified sample of the banks client base was invited via e-mail to participate in the online questionnaire (for details on the sampling procedure see Weber, Weber, and Nosić, 2012). In total 617 clients of the bank participated in the survey, 394 of which participated multiple times. 189 participants have completed at least five rounds, and 52 have participated in all nine rounds. We have a minimum of 130 observations for each of the nine rounds. We will discuss potential selection effects in section 4.4 .

We elicit beliefs about return and risk expectations in two ways, by a numerical question asking for return expectations in percentage terms and a more subjective evaluation of risk and return on a bipolar scale. The wording of the numerical question is as follows:

We would like you to make three estimates of the return of the UK stock market (FTSE all-share) by the end of the next three month.

- Your best estimate should be your best guess.

- Your high estimate should very rarely be lower than the actual outcome of the FTSE all-share (about once in 20 occasions)

- Your low estimate should very rarely be higher than the actual outcome of the FTSE all-share (about once in 20 occasions)

Please enter your response as a percentage change.

The question asks participants to predict the three-month return of the UK stock market. We use this time horizon to avoid overlapping observations as the distance between survey rounds is three month as well. One might argue that these short-term expectations will be irrelevant, if investors have a longer investment horizon. However, we find them to be highly correlated with one year expectations which were elicited twice during the survey. We suspect that three-month expectations express an investor's current optimism or pessimism about the market not limited to the particular time interval ${ }^{2}$

In a design similar to Glaser and Weber (2005), participants have to submit a best estimate as well as a high and a low estimate, which together yield a 90\%-confidence interval. We take the best estimate to represent an investor's return expectation about the UK stock

\footnotetext{
${ }^{2}$ In addition, high portfolio turnover reported below implies that short-term expectations should certainly matter.
} 
market. The high and low estimates allow calculating implicit expected volatility of investors which we use as numerical risk estimate (applying the method of Keefer and Bodily, 1983). We use this indirect way as it has been shown that people often have difficulties with numeric risk estimates (Windschitl and Wells, 1996; Dave, Eckel, Johnson, and Rojas, 2010).

Furthermore, numeric estimates may not cover all aspects of expected risks and benefits which are partly emotional (Loewenstein, Hsee, Weber, and Welch, 2001). We therefore include qualitative questions, which ask people to evaluate return and risk on a seven-point scale.

- How would you rate the returns you expect from an investment in the UK stock market (FTSE all-share) over the next 3 months?

- Over the next 3-months, how risky do you think the UK stock market (FTSE all-share) is?

In the first question answer alternatives range from "extremely bad" to "extremely good", in the second question from "not risky at all" to "extremely risky". We ask equivalent questions for investors' own portfolios held with Barclays. In total we thus collect eight belief items per investor per round. Risk tolerance of investors is measured as agreement to the statement "It is likely I would invest a significant sum in a high risk investment" (on a seven-point scale). Weber, Weber, and Nosić (2012) show that this statement is the most diagnostic within a more complete assessment of risk preferences. Besides these core variables the survey contains further queries about demographics, psychological dispositions and investment objectives. We will refer to these in the result section where appropriate.

\subsection{Survey responses}

Average numeric return expectations are relatively low before the peak of the financial crisis, then rise during the crisis and fall again, when the UK stock market recovers. Figure 2 shows the pattern in detail. In general investors tend to be more optimistic about their own portfolios: the average return expectations are consistently higher and the difference is 
non-trivial (2-4\%-points). In contrast to market expectations, average portfolio expectations remain high throughout 2009 and only decline afterwards. While market expectations are in a reasonable range adding up to an annual return of $8-12 \%$ (compared to a FTSE allshare historical return of about $8 \%$ ), the absolute level of portfolio expectations seems unrealistically high (probably explained by overconfidence cp. Merkle, 2012).

Investors in our panel (numerically) underestimate stock market risk (cp. Glaser, Langer, and Weber, 2012). The implied volatilities calculated from the confidence intervals of investors' return expectations are much lower than volatility expectations of sophisticated market participants (represented by implied option volatilities, see figure 3). While confidence intervals are too narrow in the initial survey round, investors seem to learn from observed outcomes that extreme realizations are possible and enlarge their confidence intervals. Expected volatility thus increases, but is still below implied option volatility. Furthermore after the initial adjustment the confidence intervals remain insensitive to subsequent market developments.

Qualitative risk expectations elicited on a seven-point scale reflect more closely implied market risk expectations. While it is not possible to compare the absolute magnitudes, we find a correlation of $0.78(p<0.02)$ between average qualitative risk expectations and implied option volatilities. Quite intuitively risk expectations rise with the peak of the financial crisis and then fall afterwards. However, there are two further increases in panelists' risk expectations: one without a corresponding rise in option market expectations (Sep to Dec 2009), and another, which falls together with the onset of European debt crisis (June 2010). In general expectations for own portfolio risk follow this trend, but are on average slightly lower and more stable than market expectations. It is noteworthy that investors appear to believe they can earn higher returns bearing less risk (cp. Kempf, Merkle, and Niessen, 2012).

For investigating trading behavior over time, changes in expectations are particularly important. Table 1 shows average changes for all expectation variables. We observe a signif- 
icant increase in average return and risk expectations between round one and three followed by a very mixed pattern from round three to four (further increase of qualitative return and numerical risk expectations, but sharp drop of qualitative risk expectations). Changes in expectations are less pronounced for the time after the immediate crisis. An exception is the very last survey round for which we observe strongly increasing return expectations and decreasing risk expectations. Similar to Weber, Weber, and Nosic (2012), we find that the correlations between changes of numeric and qualitative expectations are often low (return) or insignificant (risk). Stronger correlations exist between market and portfolio expectations. Average risk tolerance remains fairly stable over the whole survey period.

\subsection{Trading data}

Our data also include the trading records of all investors active in the panel survey. We include three month prior to our first survey round and three month after our last survey round. In the resulting period between June 2008 and December 2010 we observe 49,372 trades with a total trading volume of $£ 258,940,694$. Of these trades 37,022 or $75 \%$ are in stocks (63\% of trading volume). In some parts of the analysis we will concentrate on these equity transactions as they are closest related to the expectations we elicit among investors. The remaining trades include bonds, derivatives, mutual funds and ETFs. The average trader in the panel trades 84.1 times within the 2.5 year period (about three times per month), with a total trading volume of $£ 441,126$. However, the distribution is strongly skewed, the median trader trades only 33 times (about once a month; total volume $£ 72,805$ ). We observe most pronounced trading activity in the initial phase of the financial crisis; investors seem to feel a need to react to the turbulent times on asset markets.

Combining trading data with a snapshot of investors' portfolios we are able to calculate portfolio statistics for our survey period. The median portfolio is worth $£ 41,687$ (average $£ 314,663$ ) and median portfolio turnover on a per round basis (three month) is $19 \%$ (mean 
$77 \%$ ), which means that the median investor turns over his portfolio about twice in the survey period of 2.5 years, and some turn over their portfolio ten times or more.

We use the transaction records to develop several measures of risk taking behavior. As we cannot directly observe the share of risky assets as described in equation 4 , we define two alternatives that cover different aspects of risk taking. First, we consider the balance of purchases and sales of stocks in the trading records of investors, as in most cases, extending one's equity position corresponds to an increase in financial risk taking, while a reduction of one's equity position corresponds to a decrease in risk taking. We form two ratios of buys divided by total trades, based on the number and volume of investors' equity transactions, respectively. Similar ratios have been used by Ritter (1988), Grinblatt and Keloharju (2000), and Bhattacharya, Holden, and Jacobsen (2010).

We expect buy-sell imbalance to be related to investors' stock market expectations: with high return expectations for the stock market, the propensity to buy should rise relative to the propensity to sell, while the opposite effect is predicted for high risk expectations and high risk aversion. More precisely, only changes in expectations and preferences should be relevant for changes in portfolios (cp. Weber, Weber, and Nosić, 2012). However, as this is a stark theoretical assumption, we analyze both levels and changes of expectations.

A second strategy to assess financial risk taking of investors is by measures of portfolio risk such as volatility and beta (cp. Dorn and Huberman, 2005; Calvet, Campbell, and Sodini, 2007; McInish, 1982). Financial theory posits that the composition of the risky portfolio should not change, but risk is entirely adjusted via the share of the risky portfolio (fund separation, Tobin, 1958). However, in practice there are large differences in composition and risk of portfolios suggesting that investors manage their overall risk taking at least in part by portfolio risk. Therefore, we apply the theoretical predictions in equation 4 also to portfolio risk measures, and expect higher portfolio risk in response to a positive change in return expectations or a negative change in risk expectations. 
We calculate volatility of portfolios over one year and over three months horizons. We calculate portfolio beta over a one year horizon using the FTSE all-share index as corresponding market index (this choice seems justified as survey participants hold most of their investments $(>90 \%)$ in the UK stock market). Taking into account that within a volatile market environment a large part of the changes in portfolio volatility will be passively caused by changes in market volatility, we also measure relative volatility as a ratio of portfolio volatility divided by market volatility. Dorn and Huberman (2010) argue that portfolio volatility is not the correct measure of risk if investors disregard correlations between securities. They propose a value-weighted average of the return volatilities of portfolio components $(\mathrm{ACV})$, which reflects risk taking if investors mainly orient themselves at the volatility of individual securities rather than portfolio volatility. Again we consider levels and changes of these variables.

\subsection{Descriptive statistics of investor risk-taking}

For all rounds average buy-sell ratios exceed 50\%, which implies that investors are net buyers. There is almost no difference between ratios based on number of trades and volume, correlation is $0.94(p<0.01)$. We observe the highest buy-sell imbalance for late 2008, at the peak of the financial crisis, when the ratios reach about 0.66 . This suggests that investors in our sample view the crisis as an opportunity to buy at low prices. There is also large cross-sectional variation in buy-sell ratios between investors, which is crucial for our analysis of the differential influence of expectations and preferences.

Figure 4 displays portfolio volatilities of the median investor, the first-quartile investor, and third-quartile investor in our panel at the time of each survey round. The volatility of the FTSE all-share index serves for comparison. Median portfolio volatility in our panel rises from 0.26 in June 2008 to about 0.40 during the crisis, before falling to values around 0.18 for the last year of the survey. It remains constantly above market volatility, which indicates that a majority of investors hold portfolios that are riskier than the UK market portfolio. The 
difference between median portfolio volatility and market volatility is strongly significant for all rounds ( $p<0.01$, Wilcoxon signed-rank test). The third quartile shows that many investors hold very volatile portfolios compared to the market index, while the first quartile is still close to that index. The average component volatility (ACV, not displayed) exceeds these portfolio volatilities by about $40 \%$ as it does not account for diversification effects.

High portfolio volatility of investors is not due to high levels of systematic risk, as the median beta is around 0.8 over the whole sample period and most investors hold portfolios with a beta smaller than one. Instead, high volatility is driven by idiosyncratic risk as a result of a low degree of diversification. Relative volatilities suggest that investors in the immediate phase of the financial crisis try to reduce their risk exposure relative to the market, while they increase it again afterwards. Changes in beta confirm a reduction in systematic risk for the first phase of the crisis, while for later rounds the results remain inconclusive.

\section{Results}

\subsection{Investor trading behavior}

We first investigate whether market expectations drive the decision of investors to increase or decrease their stock market exposure, which is measured by buy-sell ratios. We estimate a panel tobit model with random effects as the buy-sell ratios are limited on the interval between 0 and 1 , and values on the boundaries occur frequently. We consider two specifications, one in which the absolute levels of expectations are relevant for investors, and another in which investors are supposed to react on changes in expectations.

Column 1 and 5 of table 2 show the results of the buy-sell ratios regressed on expectation levels. More precisely, we measure expectations at the time of the survey and then observe buy-sell ratios in the three month afterwards until the next survey takes place. Levels of 
expectations seem to have little effect on subsequent buying and selling behavior. Among the few marginally significant effects is a negative coefficient for risk tolerance. An explanation might be that risk tolerant investors already hold high equity positions and tend to reduce their exposure during the financial crisis. However, this effect is not robust to the inclusion of additional explanatory variables.

Changes in expectations are defined over the same time horizon (between surveys), for which buy-sell ratios are calculated. The lower number of observations in the changes regressions is due to the fact that for changes in expectations we need investors to participate in the survey for two consecutive rounds. Among the changes variables, changes in numeric return expectations exert a significant effect on buy-sell behavior (column 2 and 6). If return expectations improve investors tend to move to the buying side of the market, which is consistent with the theoretic prediction. For additional equity purchases thus not the absolute level of return expectations is relevant, but instead changes in these expectations. This result is robust to the inclusion of the levels variables (column 3 and 7 ) and of demographic variables: age, gender, wealth, and financial literacy (column 4 and 8) ${ }^{3}$. Income quite intuitively has a positive effect on buy-sell ratios as it is a proxy for additional liquidity investors might want to invest. For the remaining demographic variables we find no significant effect.

The coefficients in table 2 represent marginal effects, which directly allow an interpretation in terms of economic significance. A 10\%-point increase in return expectations will raise buy-sell ratios by about three percent. For comparison moving upward one category in income has about the same effect. In unreported results, we exclude heavy traders (the top $10 \%$ in number of trades and trading volume), as these investors might be engaged in trading activity independent of their current beliefs or other situational factors. When investors, who trade less frequently, place an order, this order might be more closely related to personal return and risk expectations. However, there is almost no change in the results under this restriction. For robustness, as the presented panel tobit model cannot account

\footnotetext{
${ }^{3}$ The exact definition of these variables is provided in the appendix
} 
for potential heteroscedasticity, we test several alternatives. A linear panel regression with clustered standard errors by individual, a fixed effects regression, and a regression with least absolute deviation (LAD) estimators. The results are reported in table 3 .

Clustered standard errors take into account the non-independence of observations within our sample. Column (1) and (4) confirms the strongly positive impact of changes in return expectations. In a fixed effects model effects are less pronounced and only marginally significant as much of the cross-sectional variation is eliminated. Part of the effect is picked

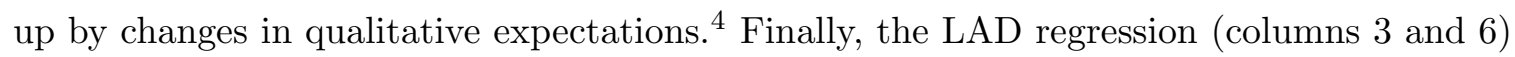
has favorable small sample properties in reducing the importance of outliers. The effect of changes in return expectations is robust to this specification.

\subsection{Investor portfolio risk}

We now turn to investor portfolio risk, which might be a more stable measure of investor risk taking. In our analysis, we interpret the volatility levels of investors' portfolios when the survey takes place as the level of risk an investor is taking at this point in time. Consequently, changes in volatility correspond to changes in risk taking 5 Similarly, we use levels and changes of other portfolio risk measures (beta, relative volatility, average component volatility).

Panel A of table 4 shows correlations between the levels of these measures; all correlations are positive as they share a common concept of risk, but the variables also capture different aspects of risk as correlations are not perfect. In particular, portfolio beta shows the weakest relation to other risk measures with coefficients between 0.23 and 0.43 . When considering

\footnotetext{
${ }^{4}$ The correlation between changes in numerical and qualitative expectations is positive but low $(0.26)$, suggesting that multicollinearity is not an issue. An explanation for the emergence of the qualitative rating effect is that the used scale lacks inter-subject comparability, but is a good predictor within subjects (fixedeffects model).

${ }^{5}$ This is a deliberate analogy to levels and changes in the hypothetical risk taking task analyzed by Weber, Weber, and Nosić (2012). In this task investors had to divide $£ 100,000$ between the FTSE-all share and a riskless asset. If we assume a volatility of 0 for the riskless asset, the volatility of the chosen portfolio is monotonically increasing with the fraction invested in the FTSE.
} 
changes (Panel B) the picture becomes even more mixed. All but one correlation are still positive, but especially for beta and three-month volatility (which is the only measure calculated over a shorter time horizon) coefficients are low. As portfolio risk measures differ, we consider most of them in our regression analysis (except relative volatility which is redundant in the levels analysis). We take the natural logarithm of the volatility variables, as volatilities are skewed within our sample.

We use market expectations as explanatory variables to avoid reverse causality inherent with portfolio expectations, as current portfolio volatility will determine expectations for future portfolio returns and volatility. Table 5 shows the results of a panel GLS regression with random effects and clustered standard errors (columns 1-4) and a fixed effects regression (columns 5-8). We find that the risk level investors take on in their portfolios depends on their expectations. In all regressions, a positive impact of numerical return expectations on volatilities and a negative impact of numerical risk expectations can be observed. Both effects are significant in most specifications, the effects are weakest for portfolio beta (also confirmed by low $R^{2}$ ). Risk tolerance and qualitative expectations mostly have no predictive power for portfolio risk. Among the demographic variables, we find significant effects for age, wealth and financial literacy. Younger investors hold more volatile portfolios, while wealthier investors tend to own less risky portfolios. This result is consistent with the findings of Dorn and Huberman (2005).

Even though using market expectations addresses the most obvious endogeneity problem, there might still be concerns that own portfolio risk determines also market expectations. Therefore, we repeat the previous analysis using lagged expectations and lagged preferences. The timing now is such that we use the expectations of each survey date to explain portfolio risk three month later. Results in 6 confirm the impact of numerical return and risk expectations on portfolio risk. The most notable difference is that in the lagged 
regression risk tolerance has a more consistent positive effect on risk taking, suggesting that it takes some time for investors to implement their risk preferences ${ }^{6}$

The interpretation in terms of economic significance is straightforward, as the dependent variable is log transformed. 10\%-points higher return expectation will induce investors to hold a portfolio with $1.65 \%$ higher volatility (1.27\% for lagged expectations). Analogously, a $10 \%$-points higher expected volatility relates to a $1.31 \%$ decrease in portfolio volatility ( $1.16 \%$ for lagged expectations).

Up to this point we dealt with state variables that give us some information which portfolio risk investors choose depending on their expectations, risk tolerance, and demographics. The panel structure of our data allows us to investigate at more detail the dynamics of these relationships. We now analyze changes of portfolio risk in response to contemporaneous changes in investor expectations and preferences. The assumption is that investors in addition to adjusting their risky share as suggested by equation 4 also change portfolio composition. We adopt a parallel approach to the levels regression and again estimate a random effects and a fixed effects model.

Table 7 shows the results of these regressions. With changes in one-year portfolio volatility (column 1 and 6) we observe the same patterns as in the levels regression. Positive changes in numerical return expectations are accompanied by increased risk taking, while higher numerical risk expectations result in decreased risk taking. In the regressions of changes in three-month volatilities on changes in expectations (see table 7), the coefficients for numerical expectations maintain their direction, but no longer reach statistical significance. This may be due to the diminished statistical power of the changes regressions, as we can only consider investors who participate in two subsequent survey rounds. However, another interpretation is that investors have more long-term objectives and do not manage

\footnotetext{
${ }^{6}$ As a further test we instrument contemporaneous expectations by lagged expectations. While the results are consistent in directionality, significance is weak. However, instrumentation is costly in terms of statistical power, as it requires consecutive observations. Additionally, there are concerns about weak instruments as correlations between expectations and lagged expectations are only around 0.3.
} 
their portfolios according to three-month volatilities. In our questionnaire, most investors state an investment horizon of three to five years.

For relative volatility and average component volatility similar patterns as for volatility emerge. In particular numerical return expectations positively influence risk taking. Changes in relative volatility most closely reflect investors' active interventions to alter portfolio risk, as raw portfolio volatility is in large part driven by changes in market volatility. As already found for levels, beta is the risk measure least related to expectations. It is likely that beta has little relevance to investors in managing the risk of their portfolios. Many private investors may not even know about this concept.

In unreported results, we substitute round dummies by market volatility, which is constant across participants and will thus capture the part of changes in portfolio volatility caused by a passive change in overall market volatility. In portfolio volatility regressions the coefficient of market volatility is about 0.7 , which means that about $70 \%$ of changes in portfolio volatilities are driven by changes in market volatility. Interestingly, changes in market volatility have a negative impact on relative volatility, suggesting investors attempt to counteract rising market volatility in an attempt to reduce their portfolio risk relative to the market.

\subsection{Volatility of trades}

We combine the two approaches of measuring financial risk taking and examine the volatility of securities investors are trading. For this purpose, all securities traded by survey participants (and for which a sufficient time series of returns is available) are sorted by return volatility throughout the survey period. We form ten volatility deciles and hereby establish a ranking of securities by their relative riskiness. We then calculate the value-weighted average of volatility decile each investor trades in. We also compute the volatility of purchases and the volatility differential between purchases and sales. The latter we interpret similar to 
buy-sell ratios as an indicator of financial risk taking; if the difference is positive an investor shifts money to more volatile securities.

Table 8 shows population averages of volatility of trades, of volatility of purchases, and the average buy-sell volatility differential. We observe that investors trade securities that are slightly more volatile than the total sample of securities (which of course has an average decile rank of 5.5). This is due to the fact that mutual funds and ETFs are less frequently traded than more volatile securities such as stocks and options. Volatility of trades and purchases is highest in the first two rounds of the survey; these are also the only rounds where the buy-sell volatility differential is positive which confirms the earlier finding that private investors in our sample seem to view the crisis as an opportunity to buy risky securities. This behavior then turns around, in particular for a period of high stock market gains in mid-2009 (cp. also figure 1). Investors move back into safer securities, a behavior that repeats itself for the final survey rounds, for which the average volatility of trades is lowest on average.

When we regress the three measures defined above on the levels of investors' expectations and risk tolerance (table 9), we find no effect on overall trade volatility, a slight effect on the volatility of purchases and a pronounced impact on the buy-sell volatility differential. This means that investors shift capital towards riskier securities in presence of high return expectations. This confirms the results of the previous section, as we now learn how investors adjust their portfolio volatility in response to positive expectations: they buy high volatility securities and sell low volatility securities. We also find that less risk-averse investors buy securities with higher volatility, in line with risk habitat theory which states that investors select securities of which volatilities are commensurate with their risk aversion (Dorn and Huberman, 2010) 17 Again older, wealthier, and more sophisticated investors trade less volatile securities. We do not report results for a regression on changes in expectations in this case, as we find no significant results.

\footnotetext{
${ }^{7}$ There is no such effect for buy-sell volatility differentials, but this is not surprising as both risk-averse and risk tolerant investors will sometimes augment and sometimes reduce risk (though on different levels).
} 


\subsection{Selection effects}

Our sample is clearly not representative, neither for the total UK population, nor for UK stock market investors, maybe not even for Barclays' online brokerage clients. We make no claim in this regard. However, we do still believe that our data are meaningful and allow to draw some inferences about investing behavior in response to personal expectations and preferences. While one has to be careful not to over-generalize our findings, we have no evidence of systematic selection in our sample, which would invalidate our results. In this section we analyze selection issues in a formal way.

Given the relatively low (but not uncommon ${ }^{8}$ response rate and the presence of attrition in our panel, there are two potential channels of selection. Specific investors might be more attracted to participate in the survey, or they leave and rejoin the sample in a non-random way, both potentially biasing our results. We have only limited data on non-participants, including age and gender, as well as some portfolio information (portfolio value, number of positions, number of transactions) $9^{9}$ We use these items as explanatory variables in a participation regression, results are reported in column 1 of table 10 . We find that male investors and investors with a higher number of holdings and transactions are more likely to participate in the survey. The latter are potentially more active and interested in financial markets, which would explain this result.

While this supports the presence of selection on observables in our sample, it may remain inconsequential for our results. We run a two-stage Heckmann selection model to test for this possibility. In column $2 \mathrm{a}$ and $2 \mathrm{~b}$, we reproduce the regression of portfolio value on expectations including the inverse Mills ratio of the first stage. The inverse Mills ratio is highly significant, again suggesting selection effect. However, our main result regarding the influence of expected return and expected risk on risk taking remains intact. It is also robust to an inclusion of the set of variables from the participation regression (column $2 \mathrm{~b}$ ).

\footnotetext{
${ }^{8}$ In similar survey studies Graham and Harvey (2001) report a response rate of 9\%, Glaser and Weber (2007) of $7 \%$, Dorn and Sengmueller (2009) of $6 \%$, compared to our $3 \%$.

${ }^{9}$ The remaining demographic variables such as income and wealth were self-reported survey items.
} 
Not surprisingly, portfolio value and number of positions are strongly negatively related to portfolio volatility, as they come along with a diversification effect. In contrast, number of transactions has a positive effect on volatility. In this specification, the significance of the inverse Mills ratio is much reduced, as the additional variables capture part of the selection effect.

We find similar results for the other levels specifications, meaning that despite selection is present in our sample, our results are mainly unaffected by it. The changes regressions by making use of the in-sample variation over time, are per se less vulnerable against this type of selection.

Next, we analyze the participation in the panel over time to detect any signs of systematic attrition. To make sure that this type of selection does not bias our main results we again use a Heckman selection model. We follow Wooldridge (1995) in estimating the participation equation separately for each round of the panel, including demographics and lagged survey variables. Instead of displaying these roundwise first stage regressions, table 10 shows a panel probit version of the participation regression (column 3). It demonstrates that wealthier investors are more likely to participate, while higher income investors are less likely to participate. Intuitively, those with higher income might be more timeconstraint. More importantly, lagged expectations do not explain subsequent participation, which means that it is not the case that e.g. optimists or more risk tolerant investors are more likely to continue the survey.

We then re-estimate in the second stage the panel regression as before, including now inverse Mills ratios from the roundwise participation regressions. This time we find no significance for the Mills ratio, suggesting no strong evidence for selection effects in the sense of systematic panel attrition. Our main results are unchanged in both specifications, whether using random effects (4a) or fixed effects (4b). We also find no evidence that the changes regression of table 7 is affected by selection. We thus conclude that while selection 
is present in our sample, it seems to have little influence on the effect of expectations and preferences on risk taking behavior.

\section{Discussion}

A main problem any research in beliefs and expectations encounters is whether the responses in a survey are valid representations of the internal beliefs of participants. The challenge is twofold, questions need to be stated in a way that participants are able to answer them in a sensible way, and participants need to be motivated to do so. For the latter we rely on the intrinsic motivation of participants as they completed the survey voluntarily, and many found it interesting enough to take part multiple times. As in most large-scale surveys, monetary incentives were not feasible, but we are in this case not aware of any obvious reason to conceal or distort beliefs in their absence ${ }^{10}$ Additionally we build on the finding of Weber, Weber, and Nosić (2012) — who use the same survey - that the elicited expectations are effective and consistent predictors of decisions, which should attenuate concerns about their validity.

The other concern that participants might not be able to express their beliefs in the question format provided to them is taken into account by the use of both, numerical and qualitative elicitation of expectations. While the numerical estimates are more demanding, in particular with respect to confidence intervals, they have the advantage of being comparable across participants. On the other hand qualitative estimates may capture aspects of value and risk not comprised in the first two moments of a distribution. Interestingly, we find with rare exceptions that only numerical expectations are relevant for actual financial risk taking decisions, which is in contrast to the results of Weber, Weber, and Nosić (2012) who establish a strong influence of qualitative expectations on allocations in the hypothetical

\footnotetext{
${ }^{10}$ For a discussion about when monetary incentives are useful see Camerer and Hogarth (1999). Other surveys that do not incentivize participants include the Michigan Survey of Consumers, the German Socioeconomic Panel and most surveys on investing behavior.
} 
investment task. We test whether the explanatory power of numerical expectations changes over to qualitative expectations if we drop numerical expectations from the regressions. In general, this is not the case and the impact of qualitative expectations remains weak.

An explanation thus has to consider the decision process in the hypothetical investment task compared to actual investing. First of all, we find our measures of financial risk taking only weakly correlated with the proportion of risky investment in the survey task which already hints at the two being different. In particular the changes of risk taking in the task and investors' portfolios are unrelated. We conjecture that the qualitative expectations are affective evaluations of the market situation, while the numerical estimates draw on more cognitive resources (cp. Kuhnen and Knutson, 2011). We would then expect these evaluations to be predictive for decisions that are made in the same "mode" of thinking 11 If the actual investment decisions of investors are preceded by a more deliberate thought process than the allocations in the hypothetical task, this would at least partly explain the greater predictive power of numerical expectations for these decisions. As we cannot fully explore the underlying mechanisms, this might be an interesting avenue for future research.

We also consider the time structure of expectations and trading, and throughout the paper we opted for an approach that tries to explain changes in investing behavior by contemporaneous changes in expectations. Another possibility would be that investors need some time to react on changes in expectations, for example because of inertia. When we use lagged level variables many of the described relationships between expectations and investment behavior can still be observed (cp. table 6) 12 However, the effects are in general equal or weaker than for contemporaneous expectations. We thus conclude that investors tend to implement their beliefs in a timely manner.

\footnotetext{
${ }^{11}$ Support for this dual-process theories of information processing and decision making can be found e.g. in Kahneman (2003).

${ }^{12} \mathrm{~A}$ similar analysis for changes is precluded by the fact, that a change $\Delta_{t+1, t}$ is mechanically (negatively) correlated to $\Delta_{t, t-1}$ over the shared observation in $\mathrm{t}$.
} 
As a complement to our research, the investor survey of Hoffmann, Post, and Pennings (2010) has an overlap of seven month with our data. Elicited expectations and portfolio characteristics show some similarities: For instance return expectations of Dutch investors also rise from September to December 2008 and further to March 2009, and trading and buying activity increases in response to the crisis. Similar to us Hoffmann, Post, and Pennings (2010) find that median portfolio volatility is higher than market volatility and closely tracks the market index. However, there are some differences as well, e.g. risk perceptions fall gradually after a peak in September 2008, while in our data they rise and then stay on a high level until March 2009. This might be due to the different wording of the question, which in Hoffmann, Post, and Pennings (2010) refers to current risk perception while our approach is more forward looking. Nevertheless taken together the findings suggest that there exist some more general properties in expectations of private investors that are not limited to a particular dataset.

In a regression of buy-sell ratios on beliefs and preferences, Hoffmann, Post, and Pennings (2010) find very different results. They use qualitative measures of expectations - which in our case remained insignificant - and demonstrate a negative effect of return expectations (levels and changes) and a positive effect of risk perception (levels and changes). This is inconsistent with financial theory and we are unable to confirm this result. However, it contributes to our impression that immediate trading behavior is hard to predict from elicited beliefs. For portfolio volatility both datasets share the intuitive positive result for risk tolerance and the insignificant result for qualitative return expectations. However, Hoffmann, Post, and Pennings (2010) identify a positive effect of risk perception on portfolio volatility. While this might again be a result of the different measurement, our findings for numerical risk expectations strongly point in an opposite direction. 


\section{Conclusion}

We investigate the functional relationship between beliefs and preferences of investors and their trading behavior. While we are still far from suggesting a definite functional form in the spirit of equation 4, our findings are a first step to improve the understanding of this complicated but fundamental relationship. We provide evidence that expectations are relevant for risk taking of investors, and that they are used in a predominantly rational and intuitive way.

Higher return expectations lead to increased risk taking in terms of volatility among investors, while higher risk expectations have the opposite effect. Even more, changes in portfolio risk are predicted by contemporaneous changes in return and risk expectations. We find evidence that investors counteract changes in market volatility by reducing their portfolio volatility relative to the market. In general the best fit of our model is achieved for long-term portfolio volatility. Changes in short-term portfolio volatility and changes in portfolio beta are less well or not at all predicted by changes in expectations. This relates directly to the question how private investors manage their portfolio risk and which risk measure is closest to their subjective experience of risk. As long-term volatility measures react strongest to investor expectations, we take this as tentative evidence that they are a good proxy for experienced risk.

Expectations have less predictive power for immediate trading activity of investors. We find a positive effect of return expectations on equity buying activity, which proxies for an adjustment of the (unobserved) risky share. However, trading is often noisy, influenced by liquidity and other exogenous trading motives, which might be a reason why we find no influence of risk expectations and preferences. Investors also engage in risk shifting within their portfolio, replacing less volatile securities by more volatile ones. We infer that contrary to two-fund separation investors use several channels to adjust their risky position. They not only increase or decrease a fixed risky portfolio, but also change this risky portfolio according to their expectations. 
Taken together our results suggest that financial theory in general correctly predicts the role of return and risk expectations for actual trading behavior. Private investors take their expectations into account to determine whether to buy or sell and whether to increase or decrease risk taking. But at the same time investors' reaction to expectations and preferences is more nuanced and more ambiguous than in the theoretical model. Not only do individual investors use different ways to alter their investment risk, but also some financial risk measures such as equity beta seem to bear little relevance for them. Instead, we conjecture that a multitude of other factors which to describe and identify is beyond the scope of this paper play a role in investment decisions. 


\section{References}

Amromin, G., and S. A. Sharpe, 2009, "Expectations of risk and return among household investors: Are their Sharpe ratios countercyclical?," Working Paper.

Barber, B. M., and T. Odean, 2000, "Trading Is Hazardous to Your Wealth: The Common Stock Investment Performance of Individual Investors," The Journal of Finance, 55(2), 773-806.

Bhattacharya, U., C. W. Holden, and S. Jacobsen, 2010, "Penny Wise, Dollar Foolish: The Left-Digit Effect in Security Trading," Working Paper.

Calvet, L. E., J. Y. Campbell, and P. Sodini, 2007, "Down or Out: Assessing the Welfare Costs of Household Investment Mistakes," Journal of Political Economy, 115(5), 707-747.

— , 2009, "Fight or Flight? Portfolio Rebalancing by Individual Investors," The Quarterly Journal of Economics, 124(1), 301-348.

Camerer, C. F., and R. M. Hogarth, 1999, "The Effects of Financial Incentives in Experiments: A Review and Capital-Labor-Production Framework," Journal of Risk and Uncertainty, 19, 7-42.

Campbell, J. Y., and L. M. Viceira, 2002, Portfolio Choice for Long-Term Investors. Oxford University Press, New York, NY.

Dave, C., C. C. Eckel, C. A. Johnson, and C. Rojas, 2010, "Eliciting Risk Preferences: When is Simple Better?," Journal of Risk and Uncertainty, 41(3), 219-243.

Dorn, D., and G. Huberman, 2005, "Talk and Action: What Individual Investors Say and What They Do," Review of Finance, 9, 437-481.

— , 2010, "Preferred risk habitat of individual investors," Journal of Financial Economics, 97(1), 155-173.

Dorn, D., and P. Sengmueller, 2009, "Trading as Entertainment?," Management Science, 55(4), 591-603.

Egan, D., C. Merkle, and M. Weber, 2010, "The Beliefs of Others - Naive Realism and Investment Decisions," Working Paper.

Ehm, C., C. Kaufmann, and M. Weber, 2012, "Volatility Inadaptability: Investors Care About Risk, But Can’t Cope with Volatility," Working Paper. 
Glaser, M., T. Langer, and M. Weber, 2012, "True Overconfidence in Interval Estimates: Evidence Based on a New Measure of Miscalibration," Journal of Behavioral Decision Making, forthcoming.

Glaser, M., and M. Weber, 2005, "September 11 and Stock Return Expectations of Individual Investors," Review of Finance, 9(2), 243-279.

— 2007, "Overconfidence and Trading Volume," The GENEVA Risk and Insurance Review, $32(1), 1-36$.

Goetzmann, W. N., and A. Kumar, 2008, "Equity Portfolio Diversification," Review of Finance, 12(3), 433-463.

Graham, J. R., and C. R. Harvey, 2001, "The theory and practice of corporate finance: evidence from the field," Journal of Financial Economics, 60, 187-243.

Grinblatt, M., and M. Keloharju, 2000, "The investment behavior and performance of various investor types: a study of Finland's unique data set," Journal of Financial Economics, 55, 43-67.

Guiso, L., P. Sapienza, and L. Zingales, 2011, "Time Varying Risk Aversion," Working Paper.

Hoffmann, A. O. I., T. Post, and J. M. E. Pennings, 2010, "Individual Investor Perceptions, Behavior, and Performance during the Financial Crisis," Working Paper.

Kahneman, D., 2003, "Maps of bounded rationality: A perspective on intuitive judgement and choice," The American Economic Review, 93(5), 1449-1475.

Keefer, D. L., and S. E. Bodily, 1983, "Three-Point Approximations for Continuous Random Variables," Management Science, 29(5), 595-609.

Kempf, A., C. Merkle, and A. Niessen, 2012, "Low Risk and High Return - Affective Attitudes and Stock Market Expectations," European Financial Management, forthcoming.

Kuhnen, C. M., and B. Knutson, 2011, "The Influence of Affect on Beliefs, Preferences, and Financial Decisions," Journal of Financial and Quantitative Analysis, 46(3), 605626.

Kumar, A., 2009, "Who Gambles in the Stock Market?," The Journal of Finance, 64(4), 1889-1933.

Lewellen, W. G., R. C. Lease, and G. G. Schlarbaum, 1977, "Patterns of Investment Strategy and Behavior Among Individual Investors," The Journal of Business, 50(3), 296-333.

Loewenstein, G. F., C. K. Hsee, E. U. Weber, and N. Welch, 2001, "Risk as Feelings," Psychological Bulletin, 127(2), 267-286. 
Markowitz, H., 1952, "Portfolio Selection," The Journal of Finance, 7(1), 77-91.

McInish, T. H., 1982, "Individual investors and risk-taking," The Journal of Economic Psychology, $2(2), 125-136$.

Merkle, C., 2012, "Financial Overconfidence Over Time - Foresight, Hindsight, and Insight of Investors," Working Paper.

Odean, T., 1998, "Volume, Volatility, Price, and Profit When All Traders Are Above Average," The Journal of Finance, 53(6), 1887-1934.

— 1999, "Do Investors Trade Too Much?," The American Economic Review, 89(5), 1279-1298.

Ritter, J. R., 1988, "The Buying and Selling Behavior of Individual Investors at the Turn of the Year," The Journal of Finance, 43(3), 701-717.

Samuelson, P. A., 1938, "A Note on the Pure Theory of Consumer's Behaviour," Economica, 5(17), $61-71$.

Sarin, R. K., and M. Weber, 1993, "Risk-Value Models," European Journal of Operational Research, $70(2), 135-149$.

Tobin, J., 1958, "Liquidity Preference as Behavior Towards Risk," The Review of Economic Studies, $25(2), 65-86$.

van Rooij, M., A. Lusardi, and R. Alessie, 2011, "Financial Literacy and Stock Market Participation," Journal of Financial Economics, 101(2), 449-472.

Vissing-Jorgensen, A., 2003, "Perspectives on Behavioral Finance: Does "Irrationality" Disappear with Wealth? Evidence from Expectations and Actions," in NBER Macroeconomics Annual 2003, Volume 18, ed. by Gertler, and Rogoff. The MIT Press, Cambridge, MA, pp. 139-208.

Weber, M., E. U. Weber, and A. Nosić, 2012, "Who takes risk and why: Determinants of changes in investor risk taking," Review of Finance, forthcoming.

Windschitl, P. D., and G. L. Wells, 1996, "Measuring Psychological Uncertainty: Verbal Versus Numeric Methods," Journal of Experimental Psychology, 2, 343-364.

Wooldridge, J. M., 1995, "Selection corrections for panel data models under conditional mean independence assumptions," Journal of Econometrics, 98(1), 115-132. 


\section{Appendix}

Description of variables

\begin{tabular}{|c|c|c|}
\hline Variable & Origin & Description \\
\hline Num. return & Survey & $\begin{array}{l}\text { Return in \% in response to survey question "We would like } \\
\text { you to make three estimates of the return of the UK stock } \\
\text { market (FTSE all-share) by the end of the next three month. } \\
\text { Your best estimate should be your best guess." }\end{array}$ \\
\hline Num. risk & Survey & $\begin{array}{l}\text { Volatility calculated from confidence intervals using the } \\
\text { methodology of Keefer and Bodily (1983) using responses to } \\
\text { survey question "We would like you to make three estimates } \\
\text { of the return of the UK stock market (FTSE all-share) by } \\
\text { the end of the next three month. Your high estimate should } \\
\text { very rarely be lower than the actual outcome of the FTSE } \\
\text { all-share (about once in 20 occasions). Your low estimate } \\
\text { should very rarely be higher than the actual outcome of the } \\
\text { FTSE all-share (about once in } 20 \text { occasions)." }\end{array}$ \\
\hline Qual. return & Survey & $\begin{array}{l}\text { Rating on scale 1-7 in response to question "How would you } \\
\text { rate the returns you expect from an investment in the UK } \\
\text { stock market (FTSE all-share) over the next } 3 \text { months?" }\end{array}$ \\
\hline Qual. risk. & Survey & $\begin{array}{l}\text { Rating on scale 1-7 in response to question "Over the next 3- } \\
\text { months, how risky do you think the UK stock market (FTSE } \\
\text { all-share) is?" }\end{array}$ \\
\hline Risk tolerance & Survey & $\begin{array}{l}\text { Agreement on Likert scale } 1-7 \text { to statement "It is likely I } \\
\text { would invest a significant sum in a high risk investment" }\end{array}$ \\
\hline$\Delta$ num. return & Survey & Num. return $(\mathrm{t})-$ num. return $(\mathrm{t}-1)$ \\
\hline$\Delta$ num. risk & Survey & Num. risk(t) - num. risk(t-1) \\
\hline$\Delta$ qual. return & Survey & Qual. return(t) - qual. return $(\mathrm{t}-1)$ \\
\hline$\Delta$ qual. risk & Survey & Qual. risk(t) - qual. risk(t-1) \\
\hline$\Delta$ risk tolerance & Survey & Risk tolerance $(\mathrm{t})$ - risk tolerance $(\mathrm{t}-1)$ \\
\hline Age & Bank data & Age of participants in years \\
\hline Gender & Bank data & Gender of participants, dummy variable 1 if male, 0 if female \\
\hline Wealth & Survey & $\begin{array}{l}\text { Self-reported wealth using } 9 \text { categories: } £ 0-10,000 ; £ 10,001- \\
50,000 ; £ 50,001-100,000 ; £ 100,001-150,000 ; £ 150,001- \\
250,000 ; £ 250,001-400,000 ; £ 400,001-600,000 ; £ 600,001- \\
1,000,000 ;>£ 1,000,000 \text {. Missing values were imputed. }\end{array}$ \\
\hline
\end{tabular}


Description of variables (continued)

\begin{tabular}{|c|c|c|}
\hline Variable & Origin & Description \\
\hline Income & Survey & $\begin{array}{l}\text { Self-reported income using } 8 \text { categories: } £ 0-20,000 ; £ 20,001- \\
30,000 ; £ 30,001-50,000 ; £ 50,001-75,000 ; £ 75,001-100,000 \text {; } \\
£ 100,001-150,000 ; £ 150,001-200,000 ;>£ 200,000 \text {. Missing } \\
\text { values were imputed. }\end{array}$ \\
\hline Fin. literacy & Survey & $\begin{array}{l}\text { Number of correct responses in a 4-item financial literacy } \\
\text { test using questions by van Rooij, Lusardi, and Alessie } \\
(2011) \text {. }\end{array}$ \\
\hline Buy-sell ratio & Bank data & $\begin{array}{l}\text { Number of purchases }- \text { number of sales divided by number } \\
\text { of total trades (range } 0 \text { to } 1 \text { ). }\end{array}$ \\
\hline $\begin{array}{l}\text { Buy-sell volume } \\
\text { ratio }\end{array}$ & Bank data & $\begin{array}{l}\text { Volume of purchases - volume of sales divided by total trad- } \\
\text { ing volume (range } 0 \text { to } 1 \text { ). }\end{array}$ \\
\hline Volatiltiy 1y & Bank data & One-year historical portfolio volatility at time t. \\
\hline Volatiltiy $3 \mathrm{~m}$ & Bank data & Three-months historical portfolio volatility at time t. \\
\hline Rel. Volatiltiy & Bank data & $\begin{array}{l}\text { One-year historical portfolio volatility divided by one-year } \\
\text { historical market volatility at time t. }\end{array}$ \\
\hline Portfolio beta & Bank data & $\begin{array}{l}\text { One-year historical portfolio beta from a one factor model } \\
\text { using the FTSE all-share index as corresponding market in- } \\
\text { dex and the LIBOR as riskfree rate. }\end{array}$ \\
\hline $\mathrm{ACV}$ & Bank data & $\begin{array}{l}\text { Average component volatility calculated using a weighted } \\
\text { average of one-year historical volatility of portfolio compo- } \\
\text { nents owned at time t. }\end{array}$ \\
\hline Trade volatility & Bank data & $\begin{array}{l}\text { Weighted average of volatility deciles for all securities traded } \\
\text { between } t \text { an } t+1 \text {. Volatilty is calculated over total survey } \\
\text { period and sorted into deciles. }\end{array}$ \\
\hline Buy volatility & Bank data & $\begin{array}{l}\text { Weighted average of volatility deciles for all securities pur- } \\
\text { chased between } t \text { an } t+1 \text {. Volatilty is calculated over total } \\
\text { survey period and sorted into deciles. }\end{array}$ \\
\hline Buy-sell vol. diff. & Bank data & $\begin{array}{l}\text { Difference of volatility for securities purchased and volatility } \\
\text { for securities sold between } t \text { and } t+1 \text {. Volatilty is calculated } \\
\text { over total survey period and sorted into deciles. }\end{array}$ \\
\hline Portfolio value & Bank data & $\begin{array}{l}\text { Portfolio value before the start of the survey (participants } \\
\text { and non-participants), and at each survey round (only par- } \\
\text { ticipants). }\end{array}$ \\
\hline $\begin{array}{l}\text { Portfolio posi- } \\
\text { tions }\end{array}$ & Bank data & $\begin{array}{l}\text { Number of holdings before the start of the survey (partici- } \\
\text { pants and non-participants), and at each survey round (only } \\
\text { participants). }\end{array}$ \\
\hline Transactions & Bank data & $\begin{array}{l}\text { Transactions in the year before the survey start (participants } \\
\text { and non-participants), and between survey round (only par- } \\
\text { ticipants). }\end{array}$ \\
\hline
\end{tabular}




\section{Tables and Figures}

Table 1: Changes in expectations of investors

\begin{tabular}{l|c|cccc|cccc}
\hline & & \multicolumn{5}{|c|}{ market } & \multicolumn{4}{c}{ own portfolio } \\
& $\Delta$ risk & $\Delta$ num. & $\Delta$ qual. & $\Delta$ num. & $\Delta$ qual. & $\Delta$ num. & $\Delta$ qual. & $\Delta$ num. & $\Delta$ qual. \\
Round & tolerance & return & return & risk & risk & return & return & risk & risk \\
\hline 2 (Dec08) & $0.23^{* *}$ & $0.020^{* *}$ & 0.12 & $0.023^{* * *}$ & $0.43^{* * *}$ & $0.026^{* *}$ & -0.09 & $0.023^{* * *}$ & $0.28^{* * *}$ \\
3 (Mar09) & -0.10 & $0.014^{*}$ & $0.20^{* *}$ & -0.001 & 0.03 & $0.030^{* * *}$ & $0.20^{* * *}$ & $-0.007^{*}$ & $0.13^{*}$ \\
4 (Jun09) & 0.07 & $-0.010^{*}$ & $0.30^{* * *}$ & $0.014^{* *}$ & $-0.77^{* * *}$ & -0.003 & $0.33^{* * *}$ & $0.018^{* * *}$ & $-0.24^{* * *}$ \\
5 (Sep09) & 0.15 & -0.008 & 0.01 & -0.008 & $0.38^{* * *}$ & $0.019^{* *}$ & 0.10 & -0.008 & 0.02 \\
6 (Dec09) & -0.14 & -0.016 & -0.03 & $-0.011^{*}$ & 0.07 & 0.014 & $-0.17^{* *}$ & -0.008 & 0.06 \\
7 (Mar10) & 0.03 & -0.004 & 0.05 & 0.004 & $-0.22^{* *}$ & $-0.047^{* *}$ & 0.11 & 0.017 & -0.12 \\
8 (Jun10) & $0.21^{*}$ & 0.008 & $-0.27^{* *}$ & -0.001 & $0.17^{*}$ & -0.010 & -0.09 & $-0.010^{*}$ & 0.13 \\
9 (Dec10) & $0.22^{*}$ & 0.009 & $0.45^{* * *}$ & $-0.015^{*}$ & $-0.29^{* * *}$ & $0.045^{* * *}$ & $0.35^{* * *}$ & 0.011 & $-0.29^{* *}$ \\
\hline
\end{tabular}

Notes: The table states changes in risk tolerance and changes in numerical and qualitative expectations of investors (compared to the previous survey round). Changes are significantly different from zero at * $10 \%$ level, **5\%-level, or ***1\%-level (one-sided t-test). 
Table 2: Buying and selling behavior

\begin{tabular}{|c|c|c|c|c|c|c|c|c|}
\hline & \multicolumn{4}{|c|}{ buy-sell ratio } & \multicolumn{4}{|c|}{ buy-sell volume ratio } \\
\hline & (1) & $(2)$ & $(3)$ & (4) & $(5)$ & (6) & $(7)$ & (8) \\
\hline num. return & 0.068 & & $0.275^{*}$ & $0.257^{*}$ & 0.040 & & $0.251^{*}$ & 0.234 \\
\hline num. risk & 0.059 & & -0.043 & -0.029 & 0.040 & & -0.124 & -0.106 \\
\hline qual. return & $-0.014^{*}$ & & 0.009 & 0.013 & -0.014 & & 0.011 & 0.015 \\
\hline qual. risk & -0.007 & & 0.018 & 0.022 & -0.008 & & 0.020 & 0.024 \\
\hline risk tolerance & $-0.010^{*}$ & & -0.010 & -0.010 & $-0.012^{* *}$ & & -0.011 & -0.009 \\
\hline$\Delta$ num. return & & $0.150^{* *}$ & $0.293^{* * *}$ & $0.288^{* * *}$ & & $0.186^{* *}$ & $0.321^{* * *}$ & $0.316^{* * *}$ \\
\hline$\Delta$ num. risk & & -0.058 & -0.074 & -0.070 & & -0.063 & -0.115 & -0.111 \\
\hline$\Delta$ qual. return & & 0.010 & 0.014 & 0.017 & & 0.012 & 0.016 & 0.019 \\
\hline$\Delta$ qual. risk & & 0.007 & 0.016 & 0.018 & & 0.010 & $0.020^{*}$ & $0.022^{*}$ \\
\hline$\Delta$ risk tolerance & & $0.012^{*}$ & 0.007 & 0.007 & & 0.011 & 0.005 & 0.006 \\
\hline age & & & & 0.002 & & & & 0.002 \\
\hline gender $($ male $=1)$ & & & & -0.089 & & & & -0.108 \\
\hline wealth & & & & -0.013 & & & & -0.010 \\
\hline income & & & & $0.034^{* * *}$ & & & & $0.028^{* *}$ \\
\hline fin. literacy & & & & -0.034 & & & & -0.034 \\
\hline $\mathrm{n}$ & 1376 & 769 & 769 & 767 & 1376 & 769 & 769 & 767 \\
\hline
\end{tabular}

Notes: The table shows results of a panel tobit regression with random effects and round dummies. Dependent variable is buy-sell ratio defined over number of trades (\# of buys/\# of total trades) for columns (1)-(4) and buy-sell volume ratio defined over trading volume (buying volume/total trading volume) for columns (5)-(8). Column (1) and (5) include levels of expectations and column (2) and (6) changes of expectations as explanatory variables. Column (3) and (7) show regressions on both, levels and changes, in column (4) and (8) additionally controlled for demographics. Demographic variables include age, gender, wealth, and financial literacy. The table displays marginal effects, coefficients are significant at *10\%-level, **5\%-level, or $* * * 1 \%$-level. 
Table 3: Robustness tests: Buying and selling behavior

\begin{tabular}{l|ccc|ccc}
\hline \multirow{2}{*}{} & \multicolumn{3}{|c|}{ buy-sell ratio } & \multicolumn{3}{c}{ buy-sell volume ratio } \\
& $(1)$ & $(2)$ & $(3)$ & $(4)$ & $(5)$ & $(6)$ \\
& clus. SE & FE & LAD & clus. SE & FE & LAD \\
\hline num. return & $0.199^{* *}$ & 0.134 & $0.343^{* *}$ & 0.173 & 0.132 & 0.174 \\
num. risk & -0.025 & 0.090 & -0.151 & -0.130 & -0.106 & -0.162 \\
qual. return & 0.014 & $0.038^{*}$ & 0.008 & 0.018 & 0.034 & 0.011 \\
qual. risk & 0.017 & 0.025 & 0.019 & 0.021 & 0.031 & 0.016 \\
risk tolerance & -0.007 & -0.023 & -0.006 & -0.006 & -0.022 & -0.009 \\
\hline$\Delta$ num. return & $0.230^{* * *}$ & 0.179 & $0.252^{* * *}$ & $0.276^{* * *}$ & $0.239^{*}$ & $0.255^{*}$ \\
$\Delta$ num. risk & -0.034 & -0.006 & -0.025 & -0.091 & -0.127 & -0.020 \\
$\Delta$ qual. return & $0.019^{* *}$ & $0.033^{* *}$ & $0.026^{*}$ & $0.024^{* *}$ & $0.035^{* *}$ & $0.028^{*}$ \\
$\Delta$ qual. risk & 0.013 & 0.015 & 0.004 & $0.019^{*}$ & 0.023 & 0.010 \\
$\Delta$ risk tolerance & 0.006 & -0.005 & 0.006 & 0.004 & -0.006 & 0.002 \\
\hline age & 0.002 & & 0.001 & 0.002 & & 0.002 \\
gender (male=1) & $-0.088^{*}$ & & $-0.146^{*}$ & $-0.118^{* *}$ & & -0.136 \\
wealth & -0.013 & & -0.006 & -0.009 & & $-0.012^{*}$ \\
income & $0.029^{* * *}$ & & $0.032^{* * *}$ & $0.022^{* *}$ & & $0.030^{* * *}$ \\
fin. literacy & -0.029 & & -0.010 & -0.030 & & -0.023 \\
\hline n & 767 & 769 & 767 & 767 & 769 & 767 \\
\hline
\end{tabular}

Notes: The table shows results of a panel GLS regression with random effects and standard errors clustered by participant (columns 1 and 4), a panel regression with fixed effects (columns 2 and 5), and a regression using least absolute deviation and bootstrapped standard errors (columns 3 and 5). Dependent variable is buy-sell ratio defined over number of trades (\# of buys/\# of total trades) for columns (1)-(3) and buysell volume ratio defined over trading volume (buying volume/total trading volume) for columns (4)-(6). Indipendent variables are as specified in table 2 . Coefficients are significant at $* 10 \%$-level, $* * 5 \%$-level, or $* * * 1 \%$-level. 
Table 4: Correlation of portfolio risk measures

\begin{tabular}{l|ccccc}
\hline \multirow{2}{*}{ PANEL A } & \multicolumn{5}{|c}{ Levels of portfolio risk } \\
& Vol 1y & Vol 3m & Rel. Vol & Beta & ACV \\
\hline Volatility 1y & 1.00 & & & \\
Volatility 3m & 0.76 & 1.00 & & & \\
Rel. volatility & 0.89 & 0.59 & 1.00 & & \\
Portfolio beta & 0.42 & 0.28 & 0.43 & 1.00 & \\
ACV & 0.64 & 0.54 & 0.50 & 0.23 & 1.00 \\
\hline PANEL B & & Changes of portfolio risk & \\
& $\Delta$ Vol 1y & $\Delta$ Vol 3m & $\Delta$ Rel. Vol & $\Delta$ Beta & $\Delta$ ACV \\
\hline$\Delta$ Volatility 1y & 1.00 & & & & \\
$\Delta$ Volatility 3m & 0.60 & 1.00 & & & \\
$\Delta$ Rel. volatility & 0.39 & 0.11 & 1.00 & & \\
$\Delta$ Portfolio beta & 0.13 & 0.05 & 0.40 & 1.00 & \\
$\Delta$ ACV & 0.60 & 0.32 & 0.06 & -0.05 & 1.00 \\
\hline
\end{tabular}

Notes: The table shows pairwise Pearson correlations of levels (Panel A) and changes (Panel B) of portfolio risk measures. All correlations are significant at 1\%-level. 


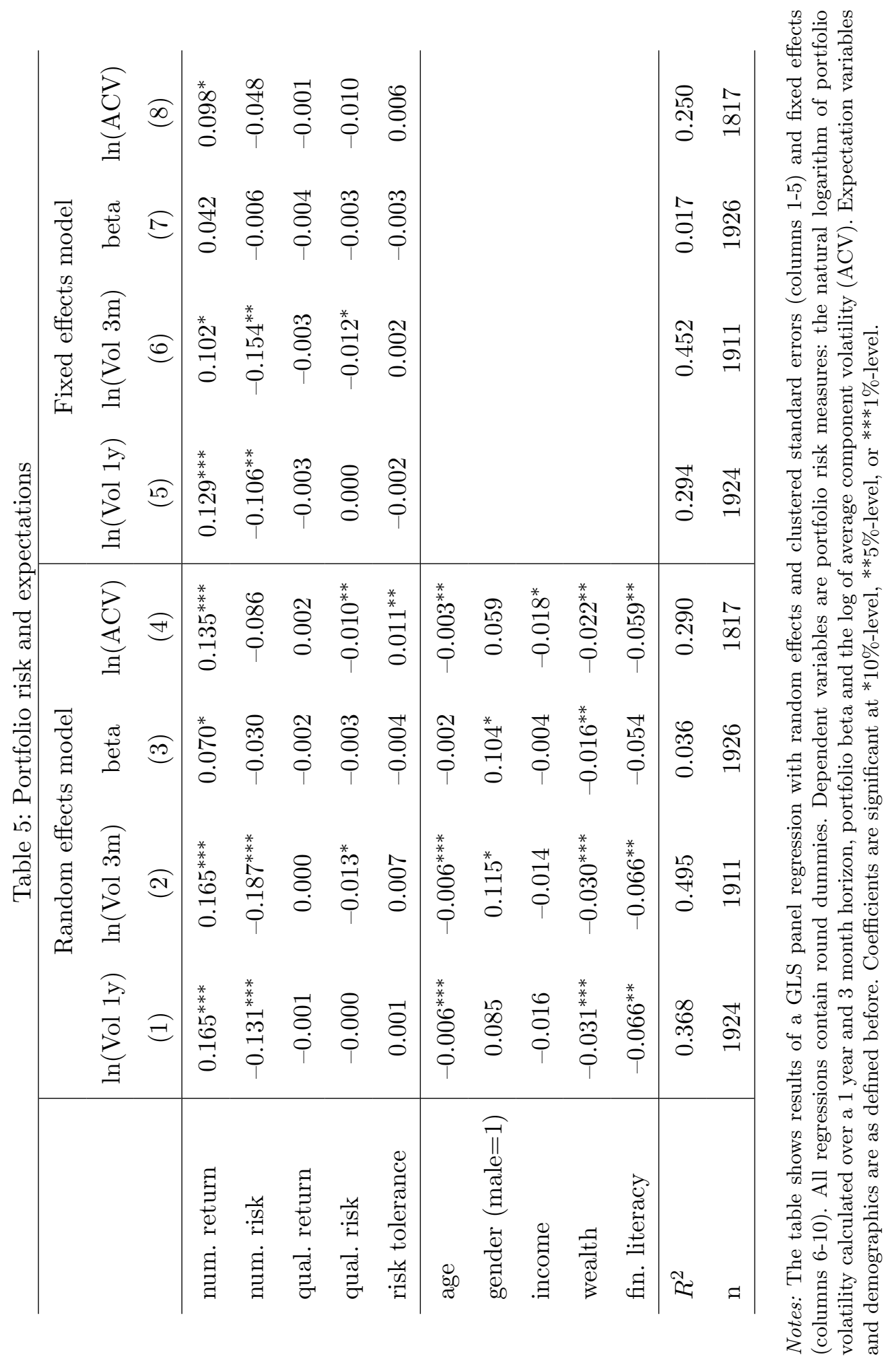




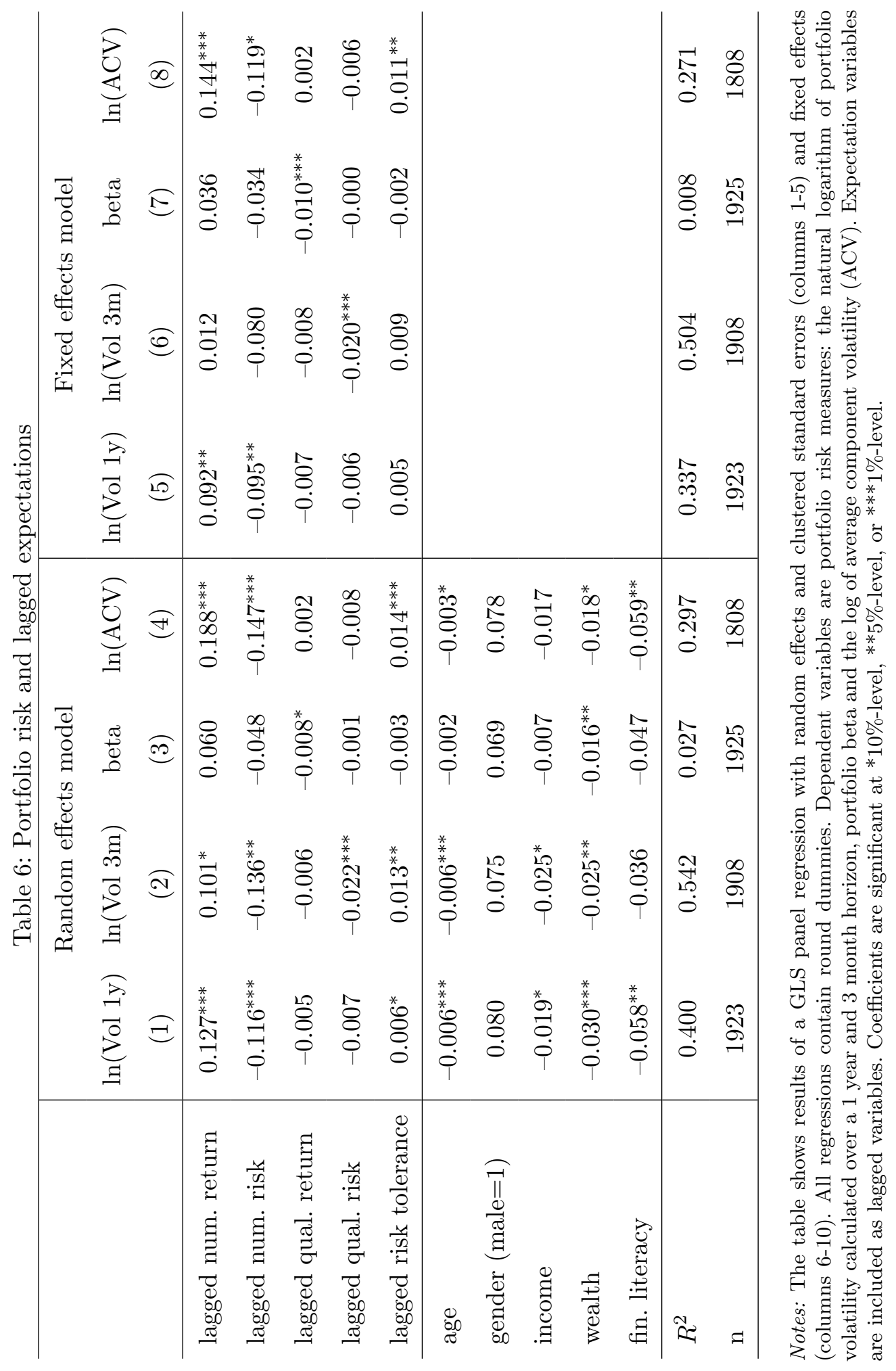




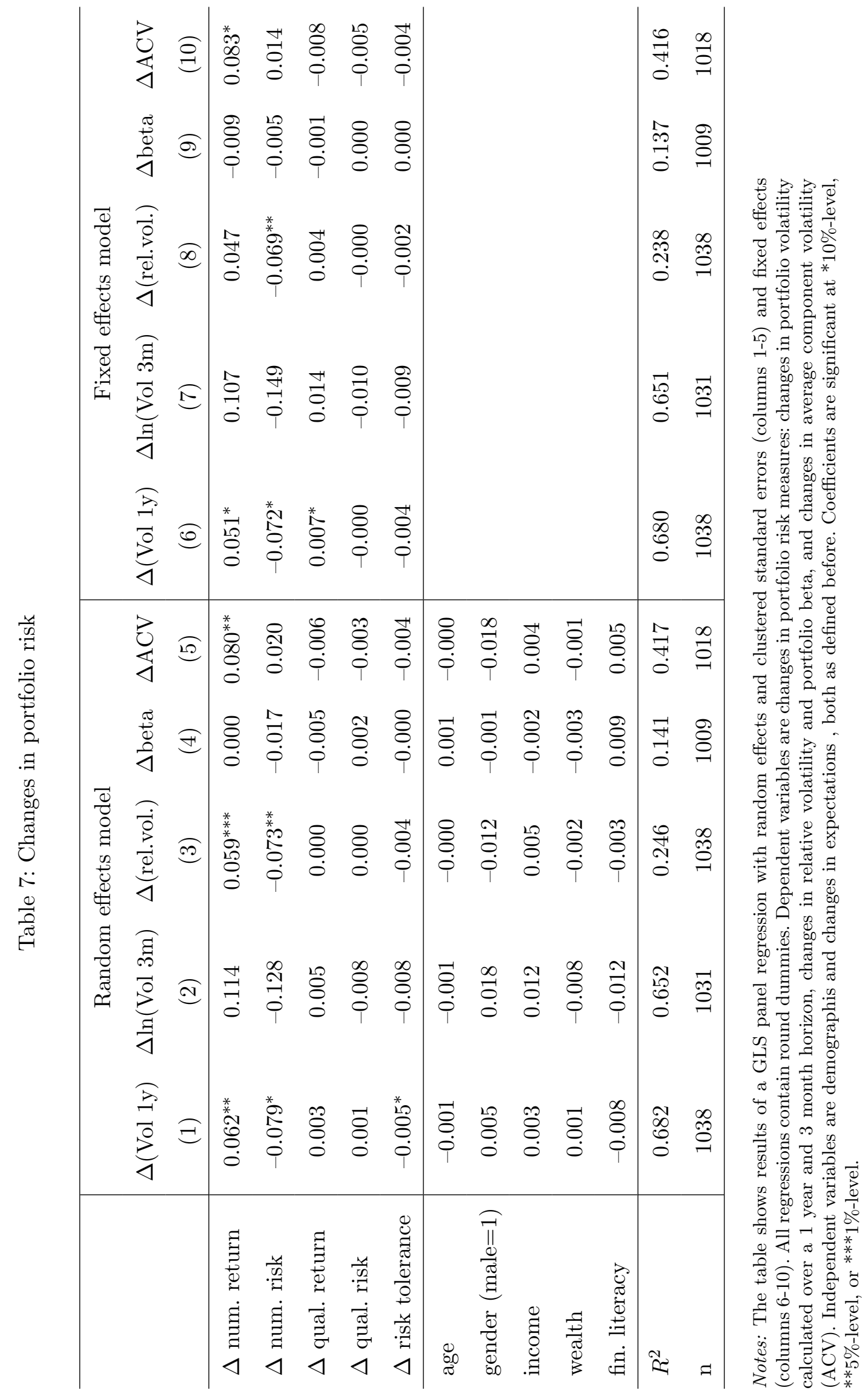


Table 8: Volatility of securities traded

\begin{tabular}{l|c|c|c}
\hline Round & trade volatility & buy volatility & buy-sell vol. diff. \\
\hline Pre-survey (Jun08-Sep08) & 6.20 & 6.42 & $0.33^{* * *}$ \\
Round 1 (Sep08-Dec08) & 6.23 & 6.37 & $0.29^{* *}$ \\
Round 2 (Dec08-Mar09) & 6.02 & 6.05 & $-0.24^{* *}$ \\
Round 3 (Mar09-Jun09) & 5.99 & 5.79 & $-0.39^{* * *}$ \\
Round 4 (Jun09-Sep09) & 6.00 & 5.88 & $-0.32^{* * *}$ \\
Round 5 (Sep09-Dec09) & 5.96 & 6.07 & -0.02 \\
Round 6 (Dec09-Mar10) & 6.03 & 6.04 & -0.06 \\
Round 7 (Mar10-Jun10) & 5.75 & 5.60 & $-0.36^{* *}$ \\
Round 8 (Jun10-Sep10) & 5.86 & 5.84 & $-0.29^{* *}$ \\
Round 9 (Sep10-Dec10) & 5.82 & 5.76 & $-0.23^{*}$ \\
\hline
\end{tabular}

Notes: The table shows for all survey rounds the average volatility decile of trades and purchases, and the average volatitity differential between purchases and sales. This difference is significant by a Wilcoxon signed-rank test at $* 10 \%$-level, $* * 5 \%$-level, or $* * * 1 \%$-level. 
Table 9: Volatility of trades explained by expectations

\begin{tabular}{l|ccc|ccc}
\hline \multirow{2}{*}{} & \multicolumn{3}{|c}{ Random effects model } & \multicolumn{3}{c}{ Fixed effects model } \\
& trade & buy & buy-sell & trade & buy & buy-sell \\
& vola & vola & vol.diff. & vola & vola & vol.diff. \\
& $(1)$ & $(2)$ & $(3)$ & $(4)$ & $(5)$ & $(6)$ \\
\hline num. return & 0.467 & $0.840^{*}$ & $1.374^{* * *}$ & 0.127 & 0.514 & $2.367^{* *}$ \\
num. risk & -0.042 & -0.431 & 0.377 & 0.201 & -0.199 & -0.421 \\
qual. return & -0.003 & 0.002 & -0.001 & -0.027 & -0.038 & -0.051 \\
qual. risk & -0.038 & -0.031 & -0.049 & -0.035 & -0.037 & -0.089 \\
risk tolerance & 0.045 & $0.082^{* * *}$ & 0.050 & -0.015 & -0.001 & -0.065 \\
\hline age & $-0.017^{* *}$ & $-0.017^{* *}$ & 0.010 & & & \\
gender (male=1) & $0.704^{* *}$ & $0.604^{*}$ & -0.077 & & & \\
income & -0.047 & -0.048 & 0.023 & & & \\
wealth & $-0.102^{* *}$ & $-0.116^{* * *}$ & -0.031 & & & \\
fin. literacy & $-0.391^{* * *}$ & $-0.376^{* * *}$ & 0.005 & & & \\
\hline$R^{2}$ & 0.085 & 0.108 & 0.041 & 0.006 & 0.030 & 0.027 \\
$n$ & 1467 & 1343 & 890 & 1467 & 1343 & 890 \\
\hline
\end{tabular}

Notes: The table shows results of panel regression with random effects with clustered standard errors (columns 1-3) or fixed effects (columns 4-6), all regressions contain round dummies. Dependent variables are the volatility of trades, the volatility of purchases and the difference between volatility of purchases and sales. Coefficients are significant at *10\%-level, **5\%-level, or ***1\%-level. 
Table 10: Sample selection

\begin{tabular}{|c|c|c|c|c|c|c|}
\hline & \multicolumn{3}{|c|}{ Participation } & \multicolumn{3}{|c|}{ Panel attrition } \\
\hline & \multirow{2}{*}{$\begin{array}{c}\text { part. } \\
(1)\end{array}$} & \multicolumn{2}{|c|}{$\ln (\mathrm{Vol} 1 \mathrm{y})$} & \multirow{2}{*}{$\begin{array}{c}\text { part. } \\
(3)\end{array}$} & \multicolumn{2}{|c|}{$\ln (\mathrm{Vol} 1 \mathrm{y})$} \\
\hline & & $(2 \mathrm{a})$ & $(2 \mathrm{~b})$ & & $(4 a)$ & $(4 b)$ \\
\hline num. return & & $0.131^{* * *}$ & $0.136^{* * *}$ & -0.065 & $0.129^{* * *}$ & $0.106^{* *}$ \\
\hline num. risk & & $-0.128^{* * *}$ & $-0.136^{* * *}$ & 0.315 & $-0.152^{* * *}$ & $-0.121^{* *}$ \\
\hline qual. return & & 0.005 & 0.007 & -0.006 & -0.003 & -0.004 \\
\hline qual. risk & & 0.004 & 0.002 & -0.010 & 0.001 & 0.000 \\
\hline risk tolerance & & 0.002 & 0.001 & -0.002 & 0.005 & 0.003 \\
\hline age & -0.000 & $-0.006^{* * *}$ & $-0.004^{* * *}$ & -0.004 & $-0.004^{* *}$ & 一 \\
\hline gender $($ male $=1)$ & $0.168^{* * *}$ & $0.219^{* * *}$ & $0.117^{*}$ & 0.192 & 0.098 & - \\
\hline income & - & -0.014 & -0.015 & $-0.122^{* * *}$ & -0.007 & - \\
\hline wealth & - & $-0.031^{* * *}$ & $-0.016^{*}$ & $0.115^{* * *}$ & $0.042^{* * *}$ & - \\
\hline fin. literacy & - & -0.040 & -0.033 & -0.043 & -0.022 & - \\
\hline portfolio value & 0.015 & & $-0.046^{* * *}$ & & & \\
\hline portfolio positions & $0.062^{* *}$ & & $-0.109^{* * *}$ & & & \\
\hline transactions & $0.064^{* * *}$ & & $0.044^{* * *}$ & & & \\
\hline inv. Mills ratio & & $0.594^{* * *}$ & $0.354^{*}$ & & -0.001 & -0.008 \\
\hline $\mathrm{n}$ & 19609 & 1536 & 1518 & 1825 & 1033 & 1033 \\
\hline
\end{tabular}

Notes: The table shows two-stage heckman selection models for participation in the survey and panel attrition. Column 1 displays a probit regression of participation including age and gender, and portfolio value, portfolio positions, and transactions (all logarithmized). Columns 2a and $2 \mathrm{~b}$ reproduce results of table 5 including the inversed Mills ratio of the first stage. Column 3 shows a probit regression for participation within survey, colunms $4 \mathrm{a}$ and $4 \mathrm{~b}$ the associated second stage estimated with random effects $(4 \mathrm{a})$ and fixed effects (4b). Coefficients are significant at *10\%-level, **5\%-level, or ***1\%-level. 
Figure 1: FTSE all-share index and survey rounds

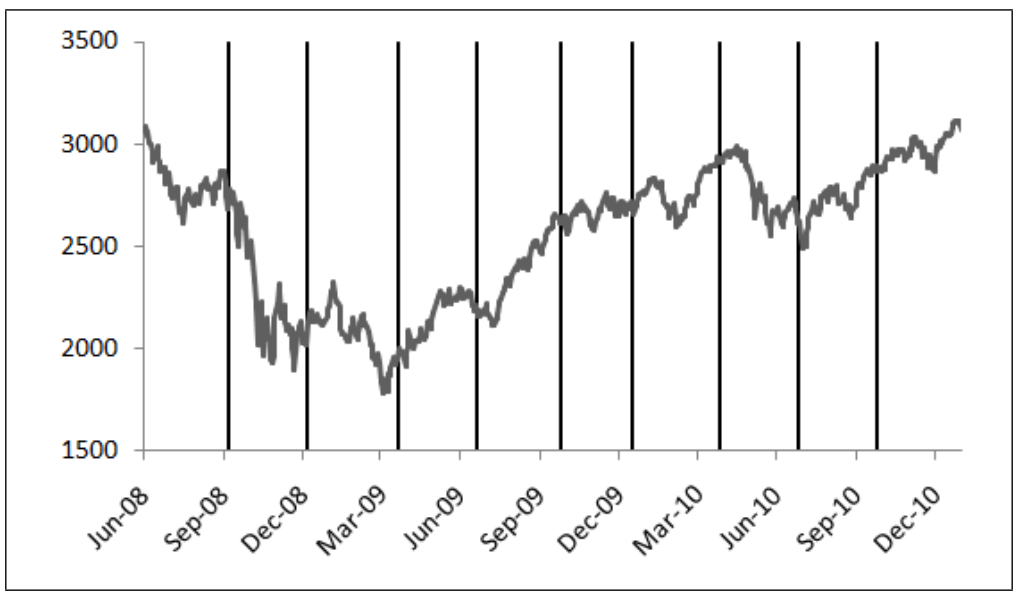

Notes: Development of the FTSE all-share index (covers 98\% of UK market capitalization) between June 2008 and December 2010. Vertical lines represent the timing of the nine survey rounds.

Figure 2: Numerical return expectations of investors

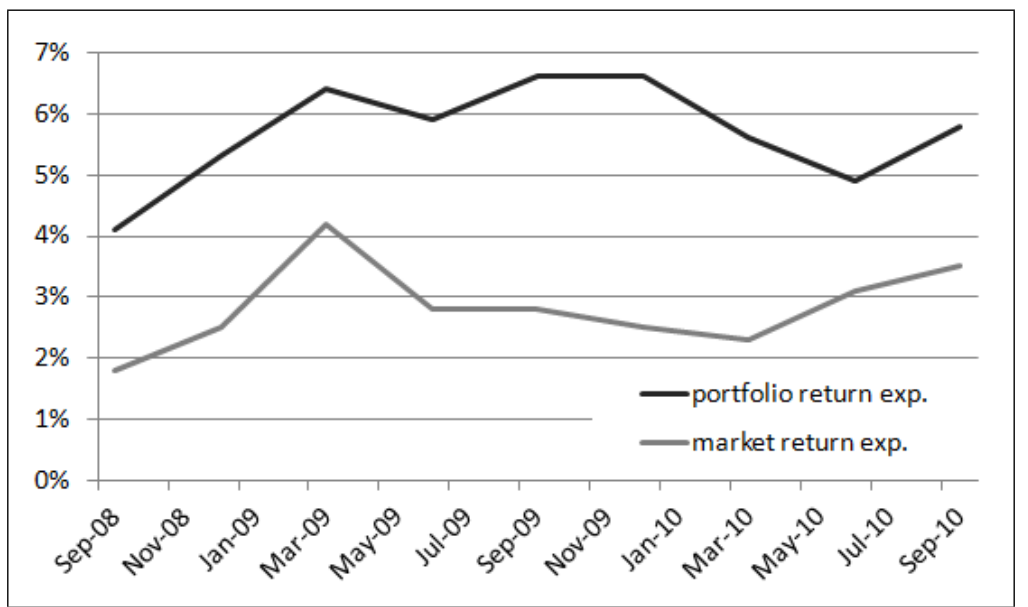

Notes: Average return expectations for the UK stock market (FTSE all share) and investors' own portfolios. 
Figure 3: Risk expectations of investors

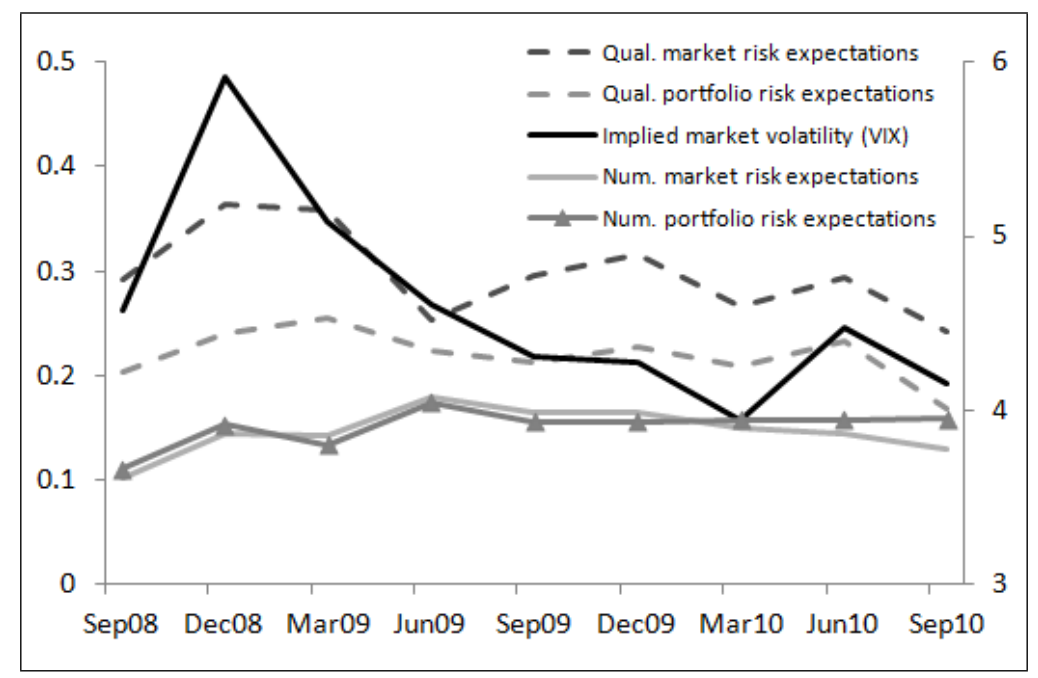

Notes: Qualitative risk expectations for market and own portfolio (scale 1-7, right axis), and numerical risk expectations as implied by confidence intervals (volatilities, left axis). For comparison implied option volatility (FTSE 100 VIX, left axis)

Figure 4: Portfolio volatility of investors and UK stock market volatility

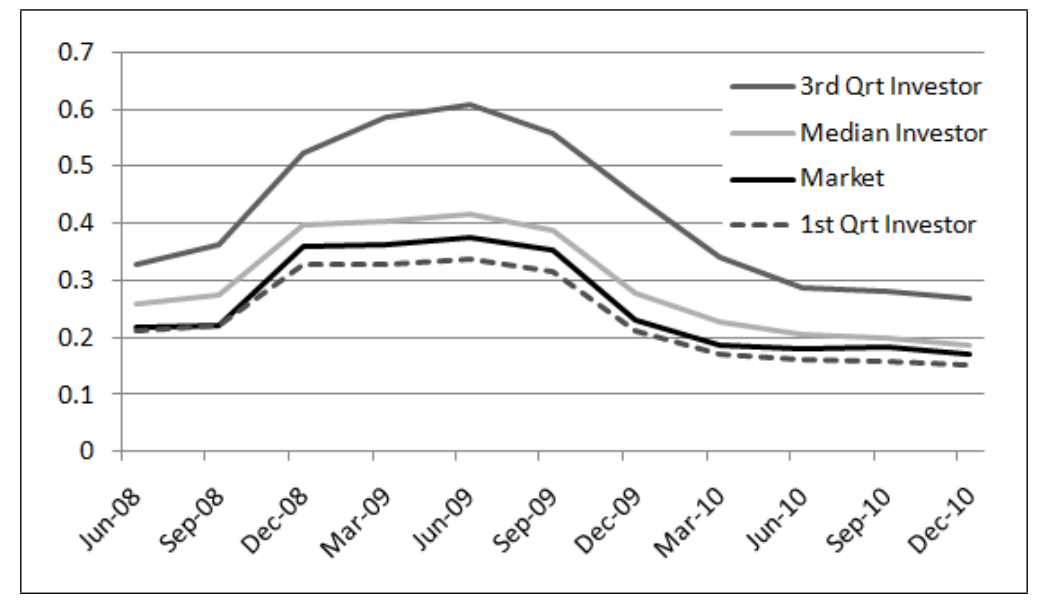

Notes: Portfolio volatility is one-year standard deviation of daily portfolio returns at point in time of survey rounds. Displayed are the median investor, the first-quartile and third-quartile investor. UK stock market volatility uses the FTSE all-share index. 